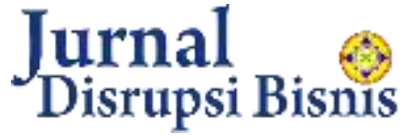

p-ISSN 2621 - 797X ; e-ISSN 2746-6841 DOI:10.32493

Jurnal Disrupsi Bisnis, Vol.5, No.1, Januari 2022 (15-20)

http://openjournal.unpam.ac.id/index.php/DRB/index

\title{
Analisis Dampak Kegiatan Pertambangan dan Penggalian terhadap PDRB Provinsi Papua
}

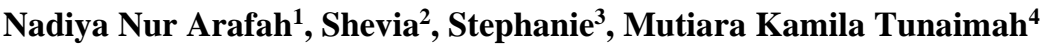 \\ 1,2,3,4Fakultas Ekonomi, Universitas Internasional Batam \\ 2041349.nadiya@uib.edu ${ }^{1 *}$
}

Received 22 Desember 2021| Revised 7 Januari 2022 | Accepted 29 Januari 2022

*Korespondensi Penulis

\begin{abstract}
Abstrak
Aktivitas pertambangan dan penggalian di Provinsi Papua sangat berpengaruh besar terhadap besarnya angka PDRB Papua. Penelitian ini dilakukan bertujuan untuk mencari tahu seberapa besar angka kontribusi sektor pertambangan dan penggalian terhadap pendapatan provinsi Papua. Metodologi penelitian ini menggunakan metode analisis kuantitatif dimana data yang di dapat adalah sumber dari data Badan Pusat Statistik. Hasil penelitian ini mencerminkan bahwa PDRB Papua mengalami peningkatan yang signifikan dengan adanya sektor pertambangan dan penggalian. Namun jika kedua sektor tersebut tidak ada pada data PDRB provinsi Papua, pendapatan Papua tidak mengalami peningkatan drastis dan stagnan. Oleh karena itu, sektor pertambangan dan penggalian sangat berpengaruh besar terhadap pendapatan Papua. Hal ini didukung dengan angka rata-rata kontribusi pertambangan dan penggalian dari tahun 2018 - 2019 sebesar 29,49\% dari total PDRB Papua.
\end{abstract}

Keywords: Produk Domestik Regional Bruto; Pertambangan; Penggalian; Papua.

\begin{abstract}
Mining and excavation activities in Papua Province have a major influence on the magnitude of Papua's GRDP. This study was conducted with the aim of finding out how much the mining and excavation sector contributes to the income of the Papua province. This research methodology uses quantitative analysis methods where the data obtained is the source of data from the Central Bureau of Statistics. The results of this study reflect that Papua's GRDP has increased significantly with the mining and excavation sector. However, if these two sectors are not included in the GRDP data for the province of Papua, Papua's income will not experience a drastic increase and become stagnant. Therefore, the mining and excavation sector is very influential on Papua's income. This is supported by the average contribution of mining and excavation from 2018 - 2019 of 29.49\% of Papua's total GRDP.
\end{abstract}

Keywords: Excavation; GRDP; Mining; Papua.

\section{PENDAHULUAN}

Papua adalah salah satu pula yang ada di Indonesia dan berlokasi di sebelah utara Australia dan merupakan bagian wilayah timur Indonesia. Provinsi Papua mempunyai luas wilayah sekitar $785.753 \mathrm{~km}^{2}$, memiliki jumlah penduduk sekitar 2,3 juta, dan memilki 29 kabupaten/kota. Secara astronomis, Provinsi Papua terletak di $0^{\circ} 20^{\prime}$ LS hingga $10^{\circ} 42^{\prime}$ LS dan $131^{\circ} \mathrm{BJ}$ hingga $151^{\circ} \mathrm{BT}$.

Potensi sumber daya mineral dan energi di Provinsi Papua cukup diketahui oleh banyak orang hingga ke luar negeri. Seorang geologis bernama J. J Dozy (Dozy, 1936) melakukan penelitian dari sampel unsur 
tembaga di Papua. Beliau pun mempublikasikan penemuannya itu kemudian melakukan kerjasama bersama Pemerintah Indonesia dengan menandatangani perjanjian kontrak karya dengan PT. Freeport McMoran Inc. Nama Freeport mungkin sudah cukup sering di dengar oleh masyarakat Indonesia. Perusahaan ini mengelola daerah seluas $100 \mathrm{~km}^{2}$ di sekitar Ertsberg, yaitu gunung yang ada di Provinsi Papua.

PT. Freeport McMoran Inc adalah perusahaan internasional yang beroperasi di Kabupaten Mimiki, Papua dan berfokus pada aktivitas tambang serta memproses bijih yang mengandung emas, tembaga dan perak yang nantinya akan diperniagakan ke seluruh dunia. Keberhasilan Freeport mengelola sumber daya yang ada di Papua terus meningkat hingga sekarang. Maka tak heran, aktivitas di bidang pertambangan dan penggalian menjadi satu hal yang sangat berdampak pada perekonomian di Papua. Dampak ekonomi berpengaruh pada aktivitas perekonomian di suatu daerah akibat adanya suatu proyek atau program (Sumardjoko, 2013).

Pembangunan ialah proses perubahan yang bertujuan untuk menaikkan tingkat hidup warga sekitar, memperluas lapangan pekerjaan, menaikkan pendapatan masyarakat, meningkatkan hubungan dengan para pelaku ekonomi, serta mengusahakan proses peralihan kegiatan ekonomi yang awalnya dari sektor primer ke sektor sekunder dan tersier (Badan Pusat Statistik, 2013). Disamping itu, Arsyad berpendapat bahwa pembangunan ekonomi merupakan suatu keadaan dimana pendapatan perkapita di suatu negara mengalami peningkatan dalam kurun waktu yang lama dikarenakan proses aktivitas ekonominya (Arsyad, 1997).

Produk Domestik Regional Bruto (PDRB) adalah jumlah nilai tambah barang ataupun jasa yang dihasilkan oleh semua unit ekonomi di suatu daerah. Menurut Todaro (Todaro, 2002) PDRB merupakan total nilai yang dihasilkan dari aktivitas perekonomian masyarakat di suatu daerah. Sedangkan BPS mengemukakan bahwa PDRB adalah total nilai tambah yang dihasilkan dari kegiatan produksi dan jasa di suatu daerah (BPS, 2016).

PDRB atas dasar harga berlaku (ADHB) dihitung berdasarkan harga yang berlaku pada periode perhitungan dan dipakai untuk melihat bagaimana struktur perekonomian. PDRB atas dasar harga konstan (ADHK) dihitung berdasarkan harga pada tahun dasar dan dipakai untuk mengukur pertumbuhan ekonomi. Untuk menghitung PDRB terdapat 3 jenis pendekatan yaitu pendekatan produksi, pengeluaran, dan pendapatan.

1. Pendekatan Produksi, merupakan jumlah nilai tambah atas bruto yang diproduksi di berbagai wilayah suatu daerah pada jangka waktu satu tahun. Unit produksi dalam pendekatan ini dibagi menjadi sembilan kelompok lapangan usaha yaitu (1) pertanian, kehutanan, peternakan, dan perikanan, (2) pertambangan dan penggalian, (3) industri pengolahan, (4) gas, listrik, air bersih, (5) konstruksi, (6) perdagangan, restoran, hotel, (7) pengangkutan dan komunikasi, (8) keuangan, jasa perusahaan, real estate, (9) jasa.

2. Pendekatan Pengeluaran, yaitu seluruh unsur biaya-biaya tambahan diantaranya seperti pengeluaran rumah tangga, konsumsi pemerintah, ekspor netto, modal tetap domestik bruto, perubahan inventori atau perlengkapan.

3. Pendekatan Pendapatan, adalah nilai kompensasi yang diterima oleh pihak yang terlibat dalam proses produksi di suatu daerah dalam jangka waktu satu tahun. Kompensasi ini mencakup gaji, upah, dan lainlain.

Data PDRB yang diterbitkan oleh BPS adalah data yang menggunakan pendekatan produksi dan pengeluaran. Data PDRB Produksi diperoleh dari instansi dan sektor terkait, berupa data harga di tingkat produsen, data produksi, data pengeluaran, data biaya untuk produksi. Data yang diperoleh melalui survei dan estimasi. Sedangkan untuk data PDRB Pengeluaran dikumpulkan dari data yang dikeluarkan resmi oleh instansi terkait seperti data pengeluaran, invesatasi pemerintah dan swasta, dan data ekspor impor. Data diperoleh melalui survei khusus. 
Selain itu, berkembanganya suatu wilayah dan ukuran keberhasilan pembangunannya dapat dilihat pada tingkat pertumbuhan ekonomi yang tercermin dari perubahan PDRB (Produk Domestik Regional Bruto). Menurut Sukirno (Sukirno, 2000) pertumbuhan ekonomi adalah kenaikan hasil per kapita dalam kurun waktu yang lama dan berfokus pada tiga hal yaitu proses hasil per kapita, dan kurun waktu yang lama. Menurutnya pula, terjadinya pertumbuhan ekonomi mencerminkan adanya perkembangan di suatu daerah (Sukirno, 2002). Selain itu, Robbert Sollow yang menggagaskan teori Neo Klasik ini berpendapat bahwa pertumbuhan ekonomi dapat terjadi berdasarkan pada penambahan persediaan faktor produksi seperti sumber daya manusia dan modal (Sollow, 1957).

Pertumbuhan ekonomi suatu daerah dapat tercermin dari besarnya angka laju pertumbuhan dari PDRB atas dasar harga konstan (Todaro dan Smith, 2008). Setiap wilayah di suatu negara terdapat sektor atau kawasan yang bersifat strategis akibat besarnya kontribusi yang diberikan dalam perekonomian wilayah. Hal ini juga demikian dengan sektor pertambangan dan penggalian yang memiliki peran penting dalam menyokong perekonomian di Papua.

Penelitian ini dilakukan sebagai upaya untuk menentukan kondisi pertumbuhan ekonomi Provinsi Provinsi pada periode 2020. Analisis dilakukan dengan menggunakan data ekonomi Provinsi Papua yang diperoleh dari Badan Pusat Statistik. Diharapkan dengan adanya penelitian ini dapat memberikan gambaran umum masyarakat, pemerintah dan lembaga-lembaga lain terhadap kondisi ekonomi saat ini di Provinsi Papua dan menjadi pertimbangan dalam pengembangan strategi yang tepat untuk melakukan kesejahteraan ekonomi.

\section{METODE}

Penelitian ini menggunakan metode analisis kuantitatif di mana penulis menggunakan sejumlah data sekunder yang didapat dari Badan Pusat Statistik (BPS) Provinsi Papua tahun 2018, 2019, dan 2020. Selain data BPS, penulis juga menggunakan beberapa informasi yang ada di internet, jurnal, dan artikel, yang kemudian digunakan untuk menganalisis data terkait PDRB Papua tahun 2018 - 2020 dan data kontribusi tiap sektor terhadap PDRB Papua. Populasi di penelitian ini adalah provinsi Papua yang mencakup 29 wilayah dan 16 jenis sektor yang digunakan. Selain itu, penelitian ini dilakukan agar mengetahui pengaruh PDRB dan kontribusi sektor pertambangan dan penggalian terhadap PDRB Papua.

Kajian ini menggunakan dua jenis variabel, diantaranya seperti:

1. Dependent Variable (Variabel Terikat)

Variabel terikat yang dipakai pada kajian ini adalah pendapatan PDRB provinsi Papua dan pertumbuhan ekonomi. Agar dapat menghitung laju pertumbuhan ekonomi provinsi Papua, khususnya pada sektor pertambangan dan penggalian, digunakan rumus berikut:

Tingkat Laju Pertumbuhan pada

Sektor Pertambangan dan Penggalian $=\frac{\text { Jumlah Pertumbuhan Ekonomi }}{\text { Jumlah Pendapatan PDRB Papua }} \times 100 \%$

2. Independent Variable (Variabel Independen)

Pendapatan PDRB Papua pada sektor pertambangan dan penggalian adalah variable yang paling berpengaruh besar terhadap pertumbuhan ekonomi Papua sehingga pendapatan asli daerah mengalami peningkatan. Penentuan nilai jumlah pendapatan daerah di tiap sektor industri diperoleh dari data Badan Pusat Statistik Indonesia pada tahun 2018 - 2020. 


\section{HASIL DAN PEMBAHASAN}

Tabel 1. Pendapatan PDRB Papua 2018-2020

\begin{tabular}{|c|c|c|c|}
\hline Industri & 2018 & 2019 & 2020 \\
\hline Pertanian, Kehutanan, dan Perikanan & 11,28 & 12,76 & 12,30 \\
\hline Pertambangan dan Penggalian & 36,64 & 23,56 & 28,27 \\
\hline Manufaktur & 2,03 & 2,27 & 2,08 \\
\hline Pengadaan Listrik dan Gas & 0,04 & 0,04 & 0,04 \\
\hline Pengadaan Air, Pengelolaan Sampah, Limbah dan Daur Ulang & 0,05 & 0,05 & 0,05 \\
\hline Konstruksi & 12,89 & 16,13 & 15,46 \\
\hline $\begin{array}{l}\text { Perdagangan Besar dan Eceran; Reparasi Mobil dan Sepeda } \\
\text { Motor }\end{array}$ & 8,94 & 10,90 & 10,52 \\
\hline Transportasi dan Pergudangan & 5,43 & 6,77 & 4,21 \\
\hline Penyediaan Akomodasi dan Makan Minum & 0,78 & 0,95 & 0,77 \\
\hline Informasi dan Komunikasi & 3,56 & 4,32 & 4,25 \\
\hline Jasa Keuangan dan Asuransi & 1,51 & 1,78 & 1,67 \\
\hline Real Estat & 2,55 & 3,05 & 2,9 \\
\hline Jasa Perusahaan & 1,14 & 1,38 & 1,23 \\
\hline $\begin{array}{l}\text { Administrasi Pemerintahan, Pertahanan dan Jaminan Sosial } \\
\text { Wajib }\end{array}$ & 8,88 & 10,81 & 11,08 \\
\hline Jasa Pendidikan & 1,76 & 2,13 & 2,06 \\
\hline Jasa Kesehatan dan Kegiatan Sosial & 1,52 & 1,87 & 1,93 \\
\hline Jasa lainnya & 1,01 & 1,22 & 1,18 \\
\hline Produk Domestik Regional Bruto & 100 & 100 & 100 \\
\hline
\end{tabular}

Sumber: BPS Papua 2018 - 2020

Pada Tabel 1 disajikan jumlah kontribusi kegiatan pertambangan dan penggalian terhadap PDRB Papua di tahun 2018-2020. Jika dilihat dari tahun 2018, sektor pertambangan dan penggalian berkontribusi sebesar 36,64\% yang mana angka ini merupakan angka terbesar dari sektor lainnya. Begitu pula dengan tahun 2019 dan 2020, sektor pertambangan dan penggalian menempati peringkat pertama dikarenaka angka kontribusinya yang besar dari sektor lain yaitu 23,56\% dan 28,27\% dari total PDRB Papua. Dari ketiga angka tersebut, di tahun 2018 dan 2020 cenderung mengalami peningkatan. Namun di tahun 2019 angkanya sempat mengalami penurunan dikarenakan adanya peralihan sistem tambang. Walaupun begitu, di tahun selanjutnya PDRB Papua mengalami peningkatan.

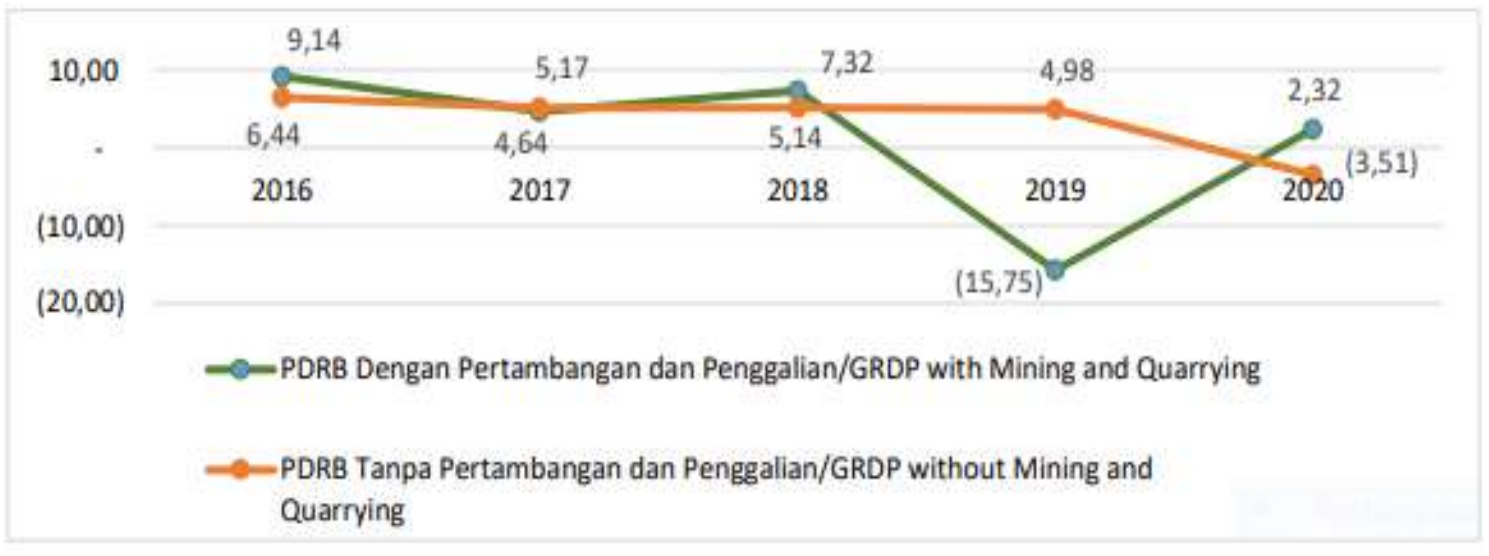

Gambar 1. Grafik PDRB Papua dengan dan tanpa Sektor Pertambangan dan Penggalian Sumber: BPS Papua 
Berdasarkan Gambar 1, kontribusi sektor pertambangan dan penggalian terhadap PDRB Papua tahun 2018 - 2020 memperoleh angka tertinggi yaitu 7,32\% dan bentuk grafik berwarna hijau terus mengalami peningkatan walaupun sempat mengalami penurunan. Namun jika dilihat garis grafik yang berwarna oranye yang menunjukkan PDRB Papua tanpa pertambangan dan penggalian, bentuk grafik tersebut hampir stagnan dan hanya sedikit saja mengalami peningkatan.

Tabel 2. Kontribusi Sektor Pertambangan dan Penggalian dalam PDRB Papua 2018-2020

\begin{tabular}{cccccc}
\hline Tahun & $\begin{array}{c}\text { PDRB (Miliar } \\
\text { Rupiah) }\end{array}$ & $\begin{array}{c}\text { Pertambangan } \\
\text { dan Pengalian } \\
\text { (juta rupiah) }\end{array}$ & $\begin{array}{c}\text { Kontribusi (\%) Sektor } \\
\text { Pertambangan dan } \\
\text { Penggalian terhadap } \\
\text { PDRB }\end{array}$ & $\begin{array}{c}\text { Laju } \\
\text { Pertumbuhan } \\
\text { PDRB (\%) }\end{array}$ & $\begin{array}{c}\text { Laju Pertumbuhan } \\
\text { Sektor } \\
\text { Pertambangan dan } \\
\text { Penggalian }\end{array}$ \\
\hline 2018 & 159.711 .852 & 58.518 .423 & 36,64 & 10,35 & 1,17 \\
\hline 2019 & 134.562 .239 & 31.702 .863 & 23,56 & $-43,27$ & $-4,58$ \\
\hline 2020 & 137.677 .571 & 38.921 .449 & 28,27 & 16,62 & 2,28 \\
\hline
\end{tabular}

Sumber: BPS Papua $2018-2020$

Laju pertumbuhan PDRB Papua tahun 2020 mengalami peningkatan dari kedua tahun sebelumnya yaitu sebesar 16,62\% sedangkan pada tahun 2019 laju pertumbuhan PDRB mencapai 23,56\%. Hal ini beriringan dengan laju pertumbuhan sektor pertambangan dan penggalian tahun 2020 yang juga mengalami peningkatan tertinggi dari dua tahun sebelumnya yaitu sebesar 2,28\%. Dapat disimpulkan bahwa pertumbuhan ekonomi Papua sangat dipengaruhi oleh kontribusi sektor pertambangan dan penggalian, sedangkan laju pertumbuhan kedua sektor tersebut dapat dikatakan berfluktuasi. Hal ini dibuktikan pada tahun 2019 dimana laju pertumbuhan PDRB Papua dan laju pertumbuhan sektor pertambangan serta penggalian mencapai titik terendah dibanding tahun 2018 dan 2020, yaitu sebesar $-43,27 \%$ dan $-4,58 \%$. Anjloknya angka tersebut diakibatkan adanya peralihan kegiatan tambang dari area terbuka ke tambang bawah tanah sehingga mengharuskan kegiatan diberhentikan sementara. Meskipun sempat menurun di tahun 2019, angka pertumbuhan kembali tumbuh di tahun 2020.

Berdasarkan hasil beberapa analisis data diatas, penyumbang terbesar terhadap pendapatan maupun struktur perekonomian daerah Papua adalah sektor pertambangan dan penggalian. Jika dilihat dari data PDRB Papua tanpa melibatkan pendapatan dari sektor pertambangan dan penggalian, pendapatan Papua tidak meningkat secara signifikan dan cenderung stagnan.

\section{SIMPULAN}

Keberadaan sektor pertambangan dan penggalian di Provinsi Papua dapat memberikan pengaruh yang kuat dan signifikan baik terhadap pendapatan dan perekonomian Provinsi Papua. Hal ini dibuktikan dengan angka kontribusi yang tinggi sektor pertambangan dan penggalian terhadap PDRB Papua di tahun 2018 2020 rata-rata sebesar $29,49 \%$ dari total PDRB.

Untuk mendukung kegiatan pertambangan dan penggalian di Provinsi Papua, perlu adanya wawasan mengenai lingkungan dan pemakaian sumber daya yang bijaksana. Oleh karena itu, perlu dibangun program atau usaha masyarakat untuk memelihara sumber daya sekitar dengan cara menjaga kebersihan lingkungan, reboisasi, membatasi penggunaan sumber daya berlebihan, dan melestarikan hubungan manusia dengan lingkungan hidup sekitar.

\section{Ucapan Terima Kasih}

Ucapan terima kasih kepada dosen pembimbing kami, Dr. Ir, Nasar Buntu L, S.T., M.M. yang telah membimbing, mengarahkan, dan mendukung kami dari awal hingga akhir serta rekan-rekan kelompok kami yang telah bekerja keras untuk menyelesaikan artikel ini. 


\section{DAFTAR PUSTAKA}

Astuti, S. I., Arso, S. P., \& Wigati, P. A. (2015). Analisis Disparitas Pendapatan Perkapita Dan Potensi Ekonomi Di Provinsi Induk Dan Provinsi Pemekaran. 3, 103-111.

Badan Pusat Statistik (2016-2020). (N.D.). Produk Domestik Regional Bruto Provinsi Papua.

Badan Pusat Statistik 2021. (2021). Statistik Daerah Provinsi Papua 2021. 55.

Bappeda Provinsi Papua. (2020). L A P O R A N Infografis Hasil Pembangunanprovinsi Papua.

Febdianti, L. A. (2017). Analisis Faktor-Faktor Yang Mempengaruhi Pdrb Di Jawa Tengah (Tahun 19852015). Journal Of Economics, Halaman 287-301, 287-301. Http://Repository.Umy.Ac.Id/Handle/123456789/15760

Indrawati, I., Sarfiah, S. N., Destiningsih, R., Ekonomi, F., Tidar, U., Tenggara, N., Papua, M., Sumatera, P., \& Bangka, K. (2019). Pembangunan Manusia Terhadap Tingkat Kemiskinan Provinsi Papua Tahun 2014-2019 Analyze The Impact Of Economic Growth , Inequality In Income Distribution , And The Human Development Index On Meliputi Lima Provinsi Yaitu Sulawesi ,. Directory Journal Ofeconomic, 2, 1068-1080.

Lim, A., Wolvinson, A., Cerina, Wibowo, R., \& Chen, S. (2021). Analisis Pendapatan Regional Wilayah Jawa Tengah Beserta Faktor-Faktor. Jurnal Sosial Dan Teknologi (Sostech), 1(6), 465-471.

Norista Gathama Putra. (2011). Pengaruh Belanja Modal Dan Belanja Operasi Terhadap Laju Pertumbuhan Ekonomi Di Provinsi Jawa Tengah. Journal Of Chemical Information And Modeling, 53(9), 21-25. Http://Www.Elsevier.Com/Locate/Scp\%0ahttp://Eprints.Polsri.Ac.Id/4852/3/Bab Ii.Pdf

Putri, N. F. A. (2018). Pengaruh Luas Lahan, Jumlah Tenaga Kerja, Kredit Perbankan Dan Infrastruktur Irigasi Terhadap Pdrb Sektor Pertanian Di Kabupaten Sumedang Periode 2005-2015. Universitas Pasundan, 11.

Raharja, I. K., Nugraha, A. A. B. S. W., \& Prameswari, A. A. A. I. (2020). Analisis Bargaining Power Indonesia Dan Pt Freeport Indonesia Dalam Negosiasi Pengalihan Kontrak Karya Menjadi Izin Usaha Pertambangan Khusus Tahun 2017 - 2018. Jurnal Hubungan Internasional, 1(2), 10-11.

Saleh, R., \& Suseno, T. (2017). Dampak Keberadaan Usaha Pertambangan Tembaga Di Papua Terhadap Perekonomian Nasional: Analisis Input - Output Impact Of The Existence Of Copper Mining In Papua On The National. 13(September), 237-252.

Sihaloho, H. (2015). Produk Domestik Regional Bruto Per Kapita Dan Pembangunan Ekonomi Yang Inklusif Dan Berkeadilan Di Kabupaten Toba Samosir. Jurnal Manajemen Dan Bisnis, 15(1), 10-19.

Suciyanti, M., Suseno, T., \& Saleh, R. (2018). Analisis Dampak Kegiatan Pertambangan Tembaga Terhadap Perekonomian Provinsi Papua. Jurnal Teknologi Mineral Dan Batubara, 14(1), 75. Https://Doi.Org/10.30556/Jtmb.Vol14.No1.2018.394

Weya, O., T.Naukoko, A., \& Kawung, G. M. (2015). Analisis Pertumbuhaan Ekonomi Dan Pendapatan Asli Daerah \& Pdrb Di Provinsi Papua. Jurnal Berkala Ilmiah Efisiensi, 15(05), 59-65. Https://Ejournal.Unsrat.Ac.Id/Index.Php/Jbie/Article/Viewfile/9695/9281 